\title{
What's in a name? Removing Women from the Women and Geography Study Group
}

Kath Browne, Joanne Norcup, Elsbeth Robson and Joanne Sharp

We are writing collectively as a quartet of Women and Geography Study Group (WGSG) members in response to a proposal that was put at the WGSG AGM this year to change the name of the group to the "Gender and Geography Research Group".

This is not the first time that there has been a proposal to change the group's name. A few years ago, the RGS suggestion that it be renamed the Women and Geography Research Group, to conform to the naming of the other research groups. This time, the call has come from within. One of the rationales for changing the group's name was that:

While there was a politics of inclusion in the naming of the group 'women and geography' when founded, this is now perceived as representing a politics of exclusion. This is reflected in the very low number of men belonging to the group and discomfort on the part of some women about the nature and purpose of the group. [WGSG discussion paper, 30th August 2011]

This and other statements suggested that gender had now become more mainstreamed, that having a space protected for women is no longer necessary. We disagree. Although we do acknowledge that "gender" as an analytical concept has been mainstreamed in geography to an extent, this was never the sole intent of the WGSG; at the same time it also sought an autonomous space from which to continue to critique and reflect upon the discipline. And this space is not purely intellectual. Although at different stages of our careers, each of us - and many, many other women in geography - have experienced both very formal forms of exclusion (including questions about our intentions to have families "vs." academic careers; a disrespect for feminist work) and the grinding everyday practices of geography departments that make us as women feel out of place (e.g. trying to socialise in departments where bonding is focused on football and beer; negotiating the combative model of seminars where the "best" question is the most aggressive). This, of course, is not only an issue for human geographers; the space for women in the WGSG also supports women physical geographers in a way that a gender-focused research group could not. Recent interventions by the WGSG on the lack of women on the Geography REF panel, and on its approach to maternity leave, highlight the on-going importance of a voice specifically for women in the discipline. 
For us, then, the proposed removal of "women" from WGSG would be a detrimental step. It negates the understanding that inequalities still exist between men and women (as well as the ways in which those who transgress this category are policed). The demise of women's studies globally has resulted in a degendering of much of the work of women's studies, a depoliticisation felt in circles in and beyond the academy (see also Sharp 2009). There can be little doubt that these places recreated hegemonic power relations around sexuality, race, cis/gendering ${ }^{1}$ and dis/ability, nevertheless they were important spaces for the safe development of knowledge, a place where the focus on women did not have to be justified,. These were places that were fought for and hard won by earlier generations of feminists ${ }^{2}$. The low numbers of men in the WGSG is the exact opposite of the other groups in the RGS which enables a different mode of engagement and way of working that challenges masculinist cultures that predominate in many other geography/academic spaces. It is a positive aspect of the group, one that recognises its purpose in challenging hegemonic power, this is difficult and uncomfortable particularly for those who occupy hegemonic positions. Similarly, masculinist practices are not defined by genitalia, 'women' who feel 'uncomfortable' are also confronted with the politicisation of the category woman through the Women in Geography Study Group.

For each of us, throughout our careers, the WGSG has provided both a material and symbolic support and presence. The material support comes in the form of sessions at conferences, meetings and connections, and, invaluable for early career scholars, were/are the WGSG weekends, predominantly, if not solely, women's space. These spaces give women a 'breather' from their everyday patriarchal, sexist, heteronormative worlds, validating their position in the academy and at times their area of research. This different way of relating pertained, of course, not only to our definition of women, but the possibility of doing something different 'from within', of supporting each other and of finding space for each other within the WGSG. It was a license to practice feminist ways of working and relating, and we do not believe that this is replicable under the guise of 'gender' in a room that is dominated by cisgendered men.

Having a WGSG is a statement, a very political one, which says that women continue to be a category worthy of analysis, underrepresented across the academy and the discipline. Our opposition to the proposed move from

\footnotetext{
${ }^{1}$ That is normatively gendered men whose sexed body as described at birth 'matches' their current and desired gender role. Cisgendered can be used to differentiate between trans/nontrans people, describing the privileges afforded to cisgendered people that are not available to all.

${ }^{2}$ Since its inception, networks have developed between WGSG researchers and wider communities of activists, educators, policy makers and NGOs. This has afforded constructively critical exchanges, has deepened understanding and underscored the necessity of the WGSG. See Whatmore and Little (1989), and Rose (1990).
} 
"women" to "gender" is not to say we shouldn't examine gender in multiple ways or that we shouldn't deconstruct the binaries of men/women. Neither are we denying the need to explore gender or to challenge the category woman, or to see in it incoherence, as well as inherent contradictions. Yet we also refuse to negate the importance of woman as a category, as a point of solidarity, as well as a means through which many of us are marginalised. The walls around the RGS building in London are covered with names and photos of mostly long-dead white colonial explorers - our discipline is framed and remembered through 'its men' (Domosh 1991). But this is not just historical. We should not forget that given the cuts to housing, benefits, the public sector under the guise of austerity and the protection of corporate interests across the UK, women are more likely to suffer the effects of 'austerity measures'. The majority of the world's poor are women, and the Millennium Development Goal most off-track to deliver by 2015 is that aiming to improve maternal health. The geography of women still matters.

Thus, having a Women and Geography Study Group, we suspect, will become more and more vital in the forthcoming months/years with the social and political changes to work, education, welfare, healthcare and employment situation in the UK and beyond. As much as researching women's lives and geographies is important, so too are the politics of negotiating the 'complex locations' (Maddrell 2009) that women in geography continue to negotiate. For us the name states the purpose of the group for the contemporary situation and into the future. We need a group that supports women in the academy working against patriarchy, subtle sexism as well as across intersectional differences, and a group that reminds the academy and beyond that women's issues, as diverse and complex as they are, continue to matter and are worthy of geographical enquiry.

\section{References}

Domosh, M. (1991) Towards a feminist historiography of geography. Transactions of the Institute of British Geographers 16:95-104.

Maddrell, A (2009) Complex Locations. Women's Geographical Work in the UK 1850-1970, RGS-IBG/ Wiley-Blackwell, Oxford.

Sharp J (2009) Geography and Gender Progress Report 3: What belongs to feminist geography? Emotion, power and change. Progress in Human Geography 33(1): 74-80.

Rose G (1990) 'Resources for teaching gender and geography', Journal of Geography in Higher Education, 14: 2, $157-162$ 
Whatmore S and Little J (1989) 'Gender and Geography', Contemporary Issues in Geography and Education 3:1. Association of Curriculum Development in Geography. London.

WGSG discussion paper, 30th August 2011. Email communication. 